\title{
Computerised tomography and intellectual impairment in the elderly
}

\author{
MARGARETA. ROBERTS A N D F. I. CA I R D ${ }^{1}$ \\ From the University Department of Geriatric Medicine, \\ University of Glasgow, Glasgow
}

\begin{abstract}
SYNOPS IS Sixty-six elderly subjects (mean age 77 years) whose mental state was assessed clinically and by simple psychometric tests have been studied by computerised tomography. The mean maximum ventricular area in the 17 mentally normal subjects was above the upper limit of normal for younger subjects, and there was a broad relationship between increasing ventricular dilatation and increasing intellectual impairment. No such clear relationship was demonstrable for measures of cortical atrophy.
\end{abstract}

Cerebral atrophy, as shown by symmetrical ventricular dilatation and widening of the cortical sulci, is considered to underly deterioration of intellectual function in the elderly, and many would consider such atrophy to be a function of ageing, and so to be expected in the brains of at least some intellectually normal elderly people (Tomlinson et al., 1968; Dayan 1973). Demonstration of cerebral atrophy in life has hitherto been dependent upon pneumoencephalography, which carries a morbidity sufficient for it to be only very rarely justifiable in the investigation of an elderly patient. The development of computerised tomography has made possible the demonstration of these abnormalities by safe non-invasive means. There appears to be a good correlation between the diagnosis of cerebral atrophy by computerised tomography and pneumoencephalography (Gawler et al., 1976; Roberts et al., 1976). The present investigation uses methods previously described by Roberts et al. (1976) to assess the degree of cerebral atrophy in 17 mentally normal old people, and 49 with varying degrees of intellectual impairment, all carefully studied by simple psychometric methods.

\section{METHODS}

Sixty-six patients, 59 of them women, aged 62 to 90 years, who were under the care of the Univer-

${ }^{1}$ Requests for reprints : F. I. Caird, University Department of Geriatric Medicine, Southern General Hospital, Glasgow G51 4TF.

(Accepted 11 May 1976.) sity Department of Geriatric Medicine, were studied by computerised tomography. A full physical examination was performed, and only those patients who showed no evidence of focal cerebral disease were included. Their mental state was assessed clinically, at a time when acute physical or situational factors were considered to be minimal, as follows:

1. Normal No evidence of mental abnormality apart from minor degrees of impairment of memory.

2. Mild impairment Definite impairment of memory and of calculating ability.

3. Moderate impairment As for mild impairment, but also disorientation for time and/or place.

4. Severe impairment As for moderate impairment, but also difficulty with self-care, in particular with dressing; most could not walk unaided, and many were incontinent of urine. All 66 were scored by the Crichton Geriatric Behavioural Rating Scale (Robinson, 1961), and all but five by a 30 -point memory and information test similar to that of Roth and Hopkins (1953). The methods of Roberts et al. (1976) were used to determine the maximum ventricular area on the computerised tomogram, from an $80 \times 80$ matrix printout of the cut showing the largest ventricular image. Cortical atrophy was assessed from the number of low-density cells, and the width of the widest sulcus was determined, from a higher tomographic cut showing cortex but no ventricle. 


\section{RESULTS}

Figure 1 shows the relationship between the three methods of assessment of mental state. The memory and information test scores fall, and the behavioural scores increase with increasing severity of mental impairment, but there is a wide scatter of values in each group, and so considerable overlap between them. The Table shows, for the four clinical groups, the mean age of the subjects, and the results of the memory and information test scores, behavioural scores, maximum ventricular areas, and the two measures of cortical atrophy. There was no significant difference in the mean age in the subjects in the four groups. The mean maximum ventricular area in the mentally normal group was 16 ( \pm SD 6$) \mathrm{cm}^{2}$; only five of the 17 had a maximum ventricular area of $10 \mathrm{~cm}^{2}$ or less, which is the best estimate of the upper limit of normal for younger subjects (Roberts et al., 1976). The mean maximum ventricular area increases with increasing severity of intellectual impairment (Fig. 2). Statistically significant correlations are demonstrable between maximum ventricular area and behavioural score at the $1 \%$ level (Fig. 3), and at less than the $1 \%$ level with the memory and information test score (Fig. 4).

There is no clear relation between the severity of intellectual impairment and either the number of low-density cells or the width of the widest cortical sulcus (Table).

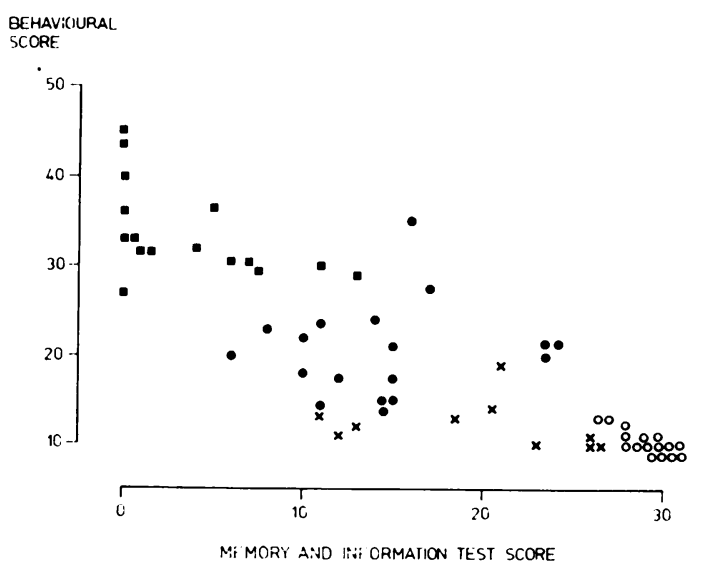

FIG. 1 Relationship between clinical assessment, memory, and information test score and behavioural score. Clinical assessment: Normal $\bigcirc$. Mild $\times$. Moderate $\bigcirc$. Severe $\square$.
T A B L E

CLINICAL AND COMPUTERISED TOMOGRAPHIC FINDINGS IN RELATION TO CLINICAL ASSESSMENT

\begin{tabular}{|c|c|c|c|c|}
\hline & \multicolumn{4}{|c|}{ Clinical assessment } \\
\hline & Normal & Mild & Moderate & Severe \\
\hline No. & 17 & 11 & 19 & 19 \\
\hline Men & 1 & 1 & 4 & 1 \\
\hline Women & 16 & 10 & 15 & 18 \\
\hline \multicolumn{5}{|l|}{ Age (yr) } \\
\hline $\begin{array}{l}\text { Mean } \perp \text { SD } \\
\text { Range }\end{array}$ & $\begin{array}{l}73 \pm 7 \\
62-84\end{array}$ & $\begin{array}{l}78 \pm 6 \\
69-90\end{array}$ & $\begin{array}{l}77 \pm 7 \\
64-85\end{array}$ & $\begin{array}{l}75 \pm 6 \\
67-86\end{array}$ \\
\hline \multicolumn{5}{|l|}{$\begin{array}{l}\text { Memory and information } \\
\text { test score }\end{array}$} \\
\hline $\begin{array}{l}\text { Mean } \pm \text { SD } \\
\text { Range }\end{array}$ & $\begin{array}{l}29 \pm 1 \\
27-30\end{array}$ & $\begin{array}{l}20 \pm 6^{*} \\
11-26\end{array}$ & $\begin{array}{r}14 \pm 5 \dagger \\
6-24\end{array}$ & $\begin{array}{l}4 \pm 4+ \\
0-13\end{array}$ \\
\hline Behavioural score & & & & \\
\hline $\begin{array}{l}\text { Mean } \pm \text { SD } \\
\text { Range }\end{array}$ & $\begin{array}{l}11 \pm 1 \\
10-13\end{array}$ & $\begin{array}{l}13 \pm 3 \\
10-19\end{array}$ & $\begin{array}{l}21 \pm 5 \\
14-35\end{array}$ & $\begin{array}{l}33 \pm 8 \\
29-45\end{array}$ \\
\hline \multicolumn{5}{|l|}{$\begin{array}{l}\text { Maximum ventricular } \\
\text { area }\left(\mathrm{cm}^{2}\right)\end{array}$} \\
\hline $\begin{array}{l}\text { Mean } \pm \text { SD } \\
\text { Range } \\
\text { 'Widest sulcus' } 12 \text { mm or }\end{array}$ & $\begin{array}{l}16 \pm 6 \\
6-26\end{array}$ & $\begin{array}{r}21 \pm 6 \\
8-29\end{array}$ & $\begin{array}{r}26 \pm 11 \\
3-49\end{array}$ & $\begin{array}{r}27 \pm 7 \\
17-37\end{array}$ \\
\hline $\begin{array}{l}\text { 'Widest sulcus' } 12 \mathrm{~mm} \text { or } \\
\text { more } \\
\text { More than } 5 \text { low-density cells }\end{array}$ & $\begin{array}{r}5 / 16 \\
10 / 16\end{array}$ & $\begin{array}{l}3 / 11 \\
5 / 11\end{array}$ & $\begin{array}{r}2 / 19 \\
10 / 19\end{array}$ & $\begin{array}{r}7 / 14 \\
11 / 13\end{array}$ \\
\hline
\end{tabular}

* 10 subjects only.

$\dagger 18$ subjects only.

$\ddagger 16$ subjects only.

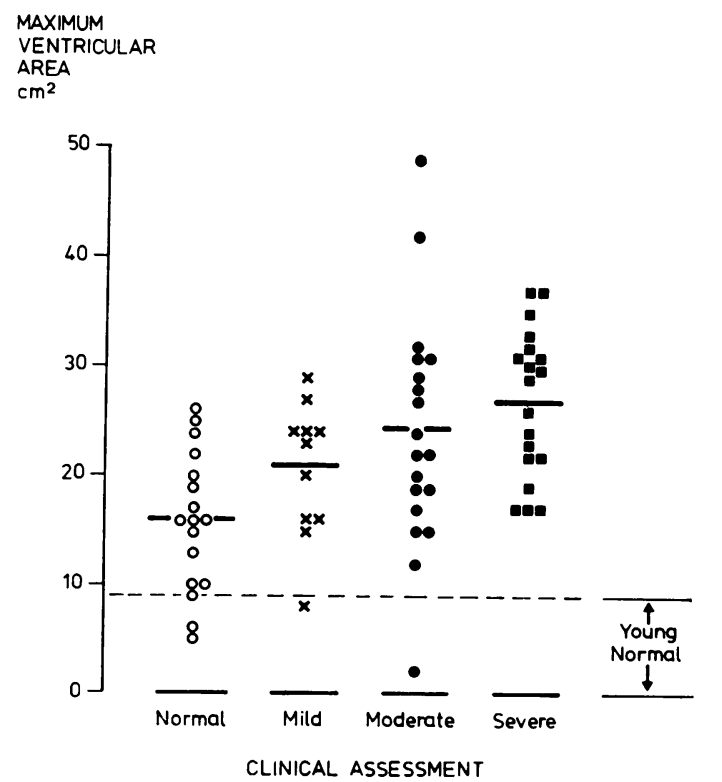

FIG. 2 Relationship between clinical assessment of intellectual impairment and maximum ventricular area. 


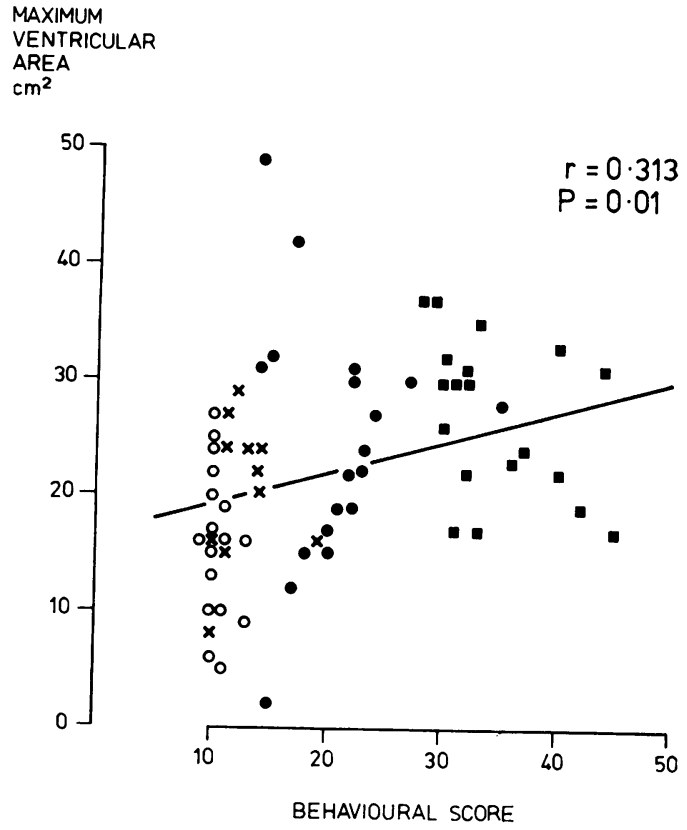

FIG. 3 Relationship between behavioural score and maximum ventricular area. Clinical assessment: Normal $\bigcirc$. Mild $\$. Moderate $\bigcirc$. Severe $\square$.

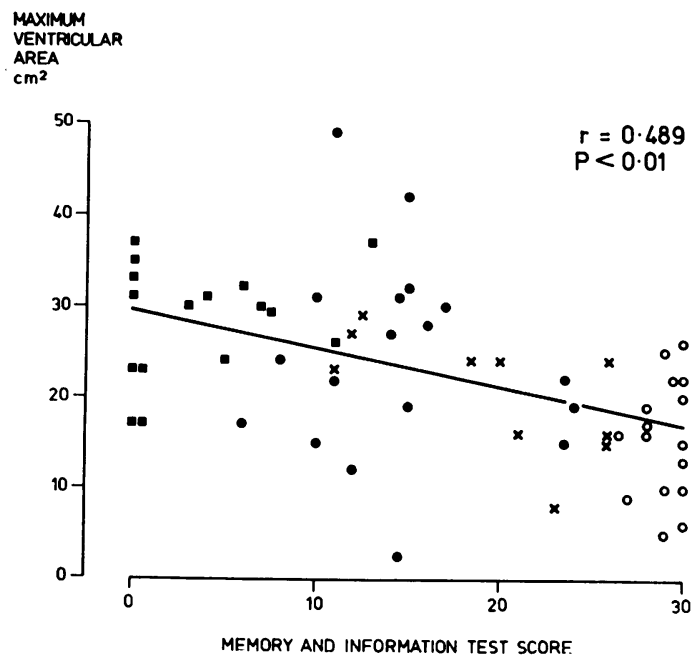

FIG. 4 Relationship between memory and information test score and maximum ventricular area. Clinical assessment: Normal $\bigcirc$. Mild $\times$. Moderate - Severe $\boldsymbol{\square}$.

\section{DISCUSSION}

The mental state of the elderly subjects in the present study was assessed by simple clinical criteria which would command agreement from most physicians with experience in geriatrics and psychogeriatrics (see, for example, Godber, 1975). Although there is considerable overlap between the four clinically determined groups for each of the two psychometric assessments taken singly, when they are taken together a reasonable separation is achieved (Fig. 1). The clinical assessment thus provides a realistic division of the range of abnormality of intellectual function encountered in the elderly.

Roberts et al. (1976) showed that the maximum ventricular area provides an adequate measure of ventricular size on computerised tomography, as compared with a number of methods of measurement of pneumoencephalograms. The simple measurements suggested by Huckman et al. (1975) and the more complex methods of Gawler et al. (1976) seem difficult to carry out in practice, although the latter at least are well related to other radiological measures of ventricular dimensions.

It is generally thought that there is an increase in size of the ventricles with age. The findings of pneumoencephalographic studies are reviewed by Bruijn (1959) and Willanger et al. (1968), but doubt has been cast upon their value by the lack of objective evidence of the normality of the subjects involved. Gyldensted and Kosteljanetz (1976) have shown a trend towards increasing ventricular size with age in normal subjects studied by computerised tomography. Tomlinson et al. (1968) were less convinced by their pathological findings in mentally normal old people. The present study strongly supports the view that slight but definite ventricular enlargement is usual in the normal elderly, but it remains uncertain at what age this process becomes apparent.

The second principal conclusion from the present study is that in the elderly there is a broad correlation between the degree of ventricular dilatation and the degree of intellectual impairment. Various pneumoencephalographic studies, predominantly in younger age groups, have demonstrated the presence of ventricular dilatation in subjects with intellectual impairment (Gosling 1955; Burhenne and Davies, 1963), and shown a correlation between the degree of dilatation and of intellectual impairment (Engeset and Lonnum 1958; Nielsen et al., 1966). Our findings (Table, Figs. 2 and 3) are in agreement, and suggest that there is in the elderly a broad relationship between increasing ventricular size and 
increasing intellectual impairment. If there is a substantial disparity between the degree of intellectual impairment and the degree of ventricular dilatation, as would be indicated by a point on Fig. 3 lying well outside those shown, further consideration of the diagnosis is indicated. If ventricular dilatation is greater than expected and the clinical picture is compatible, obstructive or normal-pressure hydrocephalus should be excluded. If ventricular dilatation is not demonstrable, but intellectual impairment appears to be considerable, the possibility of potentially remediable metabolic, toxic, or psychogenic factors in the patient's illness should be seriously pursued (Fox et al., 1975).

The failure to demonstrate any clear relationship between mental state and the evidence of cortical atrophy on computerised tomography (Table) may reflect either the inadequacies of measurement of widening of the sulci (Roberts et al., 1976) or the lack of any true relation in old age. Gyldensted and Kosteljanetz (1975) failed to show any statistically significant enlargement of cortical sulci with age on computerised tomography, but the pneumoencephalographic studies of Willanger et al. (1968) suggested the presence of undoubted cortical atrophy in old age. Tomlinson et al. (1968) were not convinced that their normal elderly subjects showed definite cortical atrophy at necropsy. Certainly the fact that in our study sulci, the width of which was assessed as $12 \mathrm{~mm}$ or more can frequently be seen in mentally normal old people must lead to caution in the use of this finding as definite evidence of 'cerebral atrophy'. This descriptive term denotes a decrease in cerebral bulk, and cannot be taken to imply a decrease in intellectual capacity.

There is a clear need for better clinicopathological correlation, which computerized tomography will make possible if it is applied to the problems of dementia in old age.

It is a pleasure to thank our colleagues for referring patients for investigation, and the radiologists of the Institute of Neurological Sciences, Glasgow, for their assistance and advice.

\section{REFERENCES}

Bruijn, G. W. (1959). Pneumoencephalography in the Diagnosis of Cerebral Atrophy. Smits: Utrecht.

Burhenne, H. J., and Davies. H. (1963). The ventricular span in cerebral pneumoencephalography. American Journal of Roentgenology, 90, 11761184.

Dayan, A. D. (1973). Neuropathology of aging. In Textbook of Geriatric Medicine and Gerontology, pp. 161-191. Edited by J. C. Brocklehurst. Churchill Livingstone: Edinburgh.

Engeset, A., and Lonnum, A. (1958). Third ventricles of $12 \mathrm{~mm}$ width or more. A preliminary report. Acta Radiologica Diagnostica, 50, 5-11.

Fox, J. H., Topel, J. L., and Huckman, M. S. (1975). Use of computerised tomography in senile dementia. Journal of Neurology, Neurosurgery, and Psychiatry, 38, 948-953.

Gawler, J., du Boulay, G. H., Bull, J. W. D., and Marshall, J. (1976). Computerised tomography (the EMIscanner): a comparison with pneumoencephalography and ventriculography. Journal of Neurology, Neurosurgery, and Psychiatry, 39, 203-211.

Godber, C. (1975). The physician and the confused elderly patient. Journal of Royal College of Physicians of London, 10, 101-112.

Gosling, R. H. (1955). The association of dementia with radiologically demonstrated cerebral atrophy. Journal of Neurology, Neurosurgery, and Psychiatry. 18, 129-133.

Gyldensted, C., and Kosteljanetz, M. (1975). Measurements of the normal hemispheric sulci with computer tomography. A preliminary study on 44 adults. Neuroradiology, 10, 147-149.

Gyldensted, C., and Kosteljanetz, M. (1976). Measurements of the normal ventricular system with computer tomography. Neuroradiology, 10, 205-215.

Huckman, M. S., Fox, J., and Topel, J. (1975). The validity of criteria for the evaluation of cerebral atrophy by computed tomography. Radiology, 116, 85-92.

Nielsen, R., Petersen, O., Thygesen, P., and Willanger, R. (1966). Encephalographic ventricular atrophy. Acta Radiologica Diagnostica, 4, 240256.

Roberts, M. A., Caird, F. I., Grossart, K. W., and Steven, J. L. (1976). Computerised tomography in the diagnosis of cerebral atrophy. Journal of Neurology, Neurosurgery, and Psychiatry, 39, 909915.

Robinson, R. A. (1961). Some problems of clinical trials in elderly people. Gerontologia Clinica, 3, 247-257.

Roth, M., and Hopkins, B. A. (1953). Psychological test performance in patients over 60. Part 1. Senile psychosis and the affective disorders of old age. Journal of Mental Science, 99, 439-450.

Tomlinson, B. E., Blessed, G., and Roth, M. (1968). Observations on the brains of non-demented old people. Journal of the Neurological Sciences, 7, 331-356.

Willanger, R., Thygesen, P., Nielsen, R., and Petersen, $O$. (1968). Intellectual impairment and cerebral atrophy: a psychological, neurological and radiological investigation. Danish Medical Bulletin, 15, 63-93. 